\title{
Ionic Messengers \\ in Development and Cancer
}

\author{
Guest Editors
}

Marc Moreau and Catherine Leclerc

Centre de Biologie du Développement, UMR 5547, Université Paul Sabatier, Toulouse, France

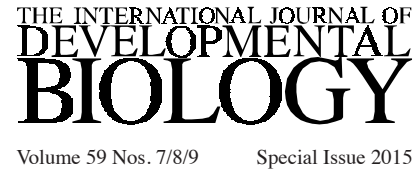





\section{Preface}

\section{Ionic messengers in development and cancer}

\section{Why development and cancer?}

It is now well recognized that early development possesses several similarities with cancer evolution, at least on a molecular basis. It was two French biologists, Jean Frédéric Lobstein (1777-1835) and Joseph Récamier (1774-1852), who simultaneously proposed in 1829 the concept of the embryonic origin of tumours. Developmental biology studies the processes that give rise to the formation of tissues and organs, involving cell growth, differentiation and morphogenesis. One can consider that tumour initiation and progression is the result of the disruption of normal cell differentiation due to mutations in gene regulatory networks. Accumulating evidence has confirmed the relationship existing between the mechanisms of development of the early embryo and tumourigenesis. The similarity of conserved pathways in development and in tumourigenesis such as those involving Wnt, FGF, Notch, BMP, Hedgehog, etc, also corroborates the idea that developmental signalling pathways are recapitulated in tumourigenesis.

\section{What is the role of ionic messengers in development and cancer?}

The idea that electrical fields can influence the development of an organism is not new. Electrical fields in cells are mainly due to the presence of channels which are permeable and selective for different ions and transporters. Modulation of their activities can affect cell cycle properties, proliferation and differentiation. The first experiment in this regard was carried out in 1892 by Wilhem Roux who subjected animal eggs to electrical fields. However, with the exception of modifications to the structure of the cytoplasm, he observed no effects on development. Since the beginning of the 20th Century it has been proposed that electrical fields may influence the development of regenerating hydroids. However, the most convincing experiments were performed by Lund (Lund 1921). Subsequently, a large body of investigators focused their work on the study of the endogenous electrical fields in relation to growth and development and to the regeneration of cells and organs in plants and animals (Burr and Northrop 1935).

This global approach continued until around 1950 (For more details see Jaffe and Nuccitelli, 1977). However by then, it still remained unclear if electrical fields where a cause or consequence of differentiation and proliferation. The role of membrane potential during fertilization was first suggested by Cole in 1938 (Cole and Spencer 1938). He observed a correlation between an increase in membrane impedance and the fast block to polyspermy. This idea was updated in the 1970's with more accurate electrophysiological techniques (for a review see Jaffe et al., 1977), although recently some authors contest this theory (Dale 2014).

The first causal role of membrane potential in development overcoming correlations was observed by Cone in the cell cycle (Cone and Tongier 1971). He showed a succession of depolarisation and hyperpolarisation events during the different phases of the cell cycle. By modification of the internal ionic concentration, he was able to obtain a reversible block of mitosis. From this period on, an extensive amount of work demonstrating depolarization in malignant cells was done (for a review, see Yang and Brackenbury 2013). During the 1970's, this work continued and was focused on the nature of ion channels and pumps responsible for membrane potential modifications, either in developmental biology, such as meiosis (Moreau et al., 1978) or fertilization (Miyazaki et al., 1972) or in tumourigenesis (Cone 1971).

Electrical fields are important for embryonic patterning, regeneration and tumour development. Membrane potential is a permanent signal which allows communication between cells, tissues and organs and has to be considered to have the same importance as biochemical signals. The activity of ion channels and pumps which maintain the electrical fields can now be dissected and visualized with new tools involving fluorescent reporters. For more details on this exciting aspect, see the reviews by M. Levin (Levin 2012; Tseng and Levin 2013).

Over the last few decades, abundant literature concerning the dissection of the role of ionic messengers in developmental biology and cell proliferation has become available. Although the roles of $\mathrm{K}^{+}, \mathrm{Cl}^{-}, \mathrm{Na}^{+}$and $\mathrm{H}^{+}$channels or exchangers have been demonstrated (for a review see Kunzelmann 2005), a large amount of research has particularly focused on the role of calcium and its causal role in development (Moreau and Leclerc 2004; Moreau et al., 1978) and in tumour progression (Stewart et al., 2014; Prevarskaya et al.,

Int. J. Dev. Biol. 59: 257-260 (2015)

doi: $10.1387 / \mathrm{ijdb} .150215 \mathrm{~mm}$ 
2014). The divalent cation $\mathrm{Ca}^{2+}$ acts as a second messenger in processes such as fertilization, proliferation, differentiation, contraction, secretion, exocytosis, gene transcription and long term memory (Berridge et al., 2000). Its specificity is mainly conferred by the spatiotemporal control of its concentration in cells, in order to elicit highly specific and regulated responses. The role of $\mathrm{Ca}^{2+}$ in development goes back to as early as 1937 with Mazia who was interested in cellular activation (Mazia, 1937). Mazia demonstrated that calcium is released upon insemination of sea urchin eggs. He proposed very accurate measurements of $\mathrm{Ca}^{2+}$ concentrations in this process. Barth and Barth in the 1960's (Barth and Barth, 1959, 1974) demonstrated the action of ions as inductors of various types of nerve, pigment cells and neuroglia.

Several types of $\mathrm{Ca}^{2+}$ channels have been shown to be involved in cell cycle progression. This is the case of voltage-gated calcium channels, transient receptor potential (TRP) channels, components of the store-operated calcium entry (SOCE), such as ORAI1 and STIM1. Among these channels, the expression of different members of the TRP family has been shown to be altered in cancer cells. Despite this, we do not yet have a full understanding of how calcium signaling is perturbed in cancer (Stewart et al., 2014).

Despite the fact that our understanding, at the molecular level, of the role of bioelectric signaling pathways, ion currents, voltage and $\mathrm{pH}$ gradients in developmental biology and tumor progression is increasing, therapeutic applications of this knowledge still appears to be far away. For the moment, research priorities seem to be on establishing the links between biochemical events, genetic regulation, and network interactions.

This Special Issue of The International fournal of Developmental Biology focuses on the role of ionic messengers and electric fields in developmental biology, bringing together reviews and original research articles dealing with gametes, early embryogenesis and patterning. The role of ionic messengers in cancer is presented through a series of papers which cover effectors controlling calcium homeostasis and a new approach to the transcriptomic analysis of the calcium toolbox. We are grateful to Juan Aréchaga who offered us the opportunity to assemble this Special Issue and would like to express our thanks to all the authors who contributed to this Issue. Although the articles cover only a part of the topics concerning the role of ionic messengers in development and cancer, they do give us an idea of future trends in this exciting field. Finally, we would like to thank all the reviewers for their pertinent evaluation of the manuscripts.

Marc Moreau and Catherine Leclerc

Toulouse, France, June 2015

\section{References}

BARTH LG \& BARTH LJ. (1959). Differentiation of cells of the Rana pipiens gastrula in unconditioned medium. J Embryol Exp Morphol 7: $210-222$.

BARTH LG \& BARTH LJ. (1974). Ionic regulation of embryonic induction and cell differentiation in Rana pipiens. Dev Biol 39: 1-22.

BERRIDGE MJ, LIPP P \& BOOTMAN MD. (2000). The versatility and universality of calcium signalling. Nat Rev Mol Cell Biol 1: 11-21.

BURR HS \& NORTHROP FSC. (1935). The electro-dynamic theory of life. Q. Rev. Biol. 10: 322-333.

COLE KS \& SPENCER JM. (1938). Electric impedance of fertilized arbacia egg suspensions. J Gen Physiol 21: 583-590.

CONE CD. (1971). Unified theory on the basic mechanism of normal mitotic control and oncogenesis. $J$ Theor Biol 30: 151-181.

CONE CD \& TONGIER M. (1971). Control of somatic cell mitosis by simulated changes in the transmembrane potential level. Oncology 25: 168-182.

DALE B. (2014). Is the idea of a fast block to polyspermy based on artifact? Biochem Biophys Res Commun 450: 1159-1165.

JAFFE LF \& NUCCITELLI R. (1977). Electrical controls of development. Annu Rev Biophys Bioeng 6: 445-476.

KUNZELMANN K. (2005). Ion channels and cancer. J Membr Biol 205: 159-173.

LEVIN M. (2012). Molecular bioelectricity in developmental biology: new tools and recent discoveries: control of cell behavior and pattern formation by transmembrane potential gradients. Bioessays 34: 205-217.

LOBSTEIN, J.F. (1829) Traité d'anatomie pathologique. Strasbourg, 2 vol in-8

LUND EJ. (1921). Influencia experimental de la polaridad orghica por medio de la corriente electrica. J. Exp. Zool. 34: 471-493.

MAZIA D.(1937). The release of calcium in Arbacia eggs on fertilization. J. Cell Comp. Physiol. 10: 291-304.

MIYAZAKI S, TAKAHASHI K \& TSUDA K. (1972). Calcium and sodium contributions to regenerative responses in the embryonic excitable cell membrane. Science 176: 1441-1443.

MOREAU M, GUERRIER P, DOREE M \& ASHLEY CC. (1978). Hormone-induced release of intracellular Ca2+ triggers meiosis in starfish oocytes. Nature 272: 251-253.

MOREAU M \& LECLERC C. (2004). The choice between epidermal and neural fate: a matter of calcium. Int J Dev Biol 48: 75-84.

PREVARSKAYA N, OUADID-AHIDOUCH H, SKRYMA R \& SHUBA Y. (2014). Remodelling of Ca2+ transport in cancer: how it contributes to cancer hallmarks? Philos Trans $R$ Soc Lond B Biol Sci 369: 20130097.

RÉCAMIER, J. (1829). Recherches sur le traitement du cancer par compression méthodique et histoire générale de la maladie, Paris, 2 vol. in-8

STEWART TA, YAPA KT \& MONTEITH GR. (2015). Altered calcium signaling in cancer cells. Biochim Biophys Acta. 1848: $2502-2511$.

TSENG A \& LEVIN M. (2013). Cracking the bioelectric code: Probing endogenous ionic controls of pattern formation. Commun Integr Biol 6: e22595.

YANG M \& BRACKENBURY WJ. (2013). Membrane potential and cancer progression. Front Physiol 4: 185. 


\section{Further Related Reading, published previously in the Int. J. Dev. Biol.}

Dual roles of voltage-gated sodium channels in development and cancer

Faheemmuddeen Patel and William J. Brackenbury

Int. J. Dev. Biol. In Press

Coordinated modulation of cellular signaling through ligand-gated ion channels in Hydra vulgaris (Cnidaria, Hydrozoa)

Paola Pierobon

Int. J. Dev. Biol. (2012) 56: 551-565

Xp54nrb a RNA-binding protein isolated from a Ca2+-dependent screen is expressed in neural structures during Xenopus laevis development.

Neant I, Deisig N, Scerbo P, Leclerc C and Moreau M

Int. J. Dev.Biol (2011) 55: 923-931.

Ion channels that control fertility in mammalian spermatozoa

Betsy Navarro, Yuriy Kirichok, Jean-Ju Chung and David E. Clapham

Int. J. Dev. Biol. (2008) 52: 607-613.

The choice between epidermal and neural fate: a matter of calcium

Moreau M. and Leclerc C.

Int. J. Dev. Biol. (2004) 48: 75-84.

Tissue-specific distribution and variation of the channel-forming protein ductin during development of Drosophila melanogaster.

$\mathrm{J}$ Bohrmann and A Bonafede

Int. J. Dev. Biol. (2000) 44: 883-890

Expression of L-type Ca2+ channel during early embryogenesis in Xenopus laevis. G Drean, C Leclerc, A M Duprat and M Moreau

Int. J. Dev. Biol. (1995) 39: 1027-1032

Expression of membrane targeted aequorin in Xenopus laevis oocytes.

Daguzan, C., Nicolas, M.T., Mazars, C., Leclerc, C. and Moreau, M.

Int. J. Dev. Biol. (1995) 39: 653-657.

4-aminopyridine acts as a weak base and a $\mathrm{Ca} 2+$ mobilizing agent in triggering oocyte meiosis reinitiation and activation in the japanese clam Ruditapes phillipinarum.

Gobet, I., Lippai, M., Tomkowiak, M., Leclerc, C., Moreau, M. and Guerrier, P.

Int. J. Dev. Biol. (1995). 39: 485-491.

Thimerosal triggers meiosis reinitiation in oocytes of the japanese clam Ruditapes philippinarum by eliciting an intracellular $\mathrm{Ca} 2+$ surge.

Lippai, M., Gobet, I., Tomkowiak, M., Durocher, Y., Leclerc, C., Moreau, M. and Guerrier, P. Int. J. Dev. Biol. (1995). 39: 401-407.

Regulation of $\mathrm{Na}+\mathrm{K}+$ ATPase during meiotic maturation of Pleurodeles waltl oocytes. Role of calcium.

Canaux, S., Foulquier, F. Duprat, A.M. and Moreau, M.

Int. J. Dev. Biol. (1995). 39: 327-333.

Transient expression of SPARC in the dorsal axis of early Xenopus embryos: correlation with calcium-dependent adhesion and electrical coupling.

S Damjanovski, L Malaval and M J Ringuette

Int. J. Dev. Biol. (1994) 38: 439-446

Electrically fused-egg induction and its development in the goldfish, Carassius auratus.

E Yamaha and $\mathrm{F}$ Yamazaki

Int. J. Dev. Biol. (1993) 37: 291-298

Polar ionic currents around embryos of Lymnaea stagnalis during gastrulation and organogenesis.

R Créton, D Zivkovic, G Zwaan and R Dohmen

Int. J. Dev. Biol. (1993) 37: 425-431

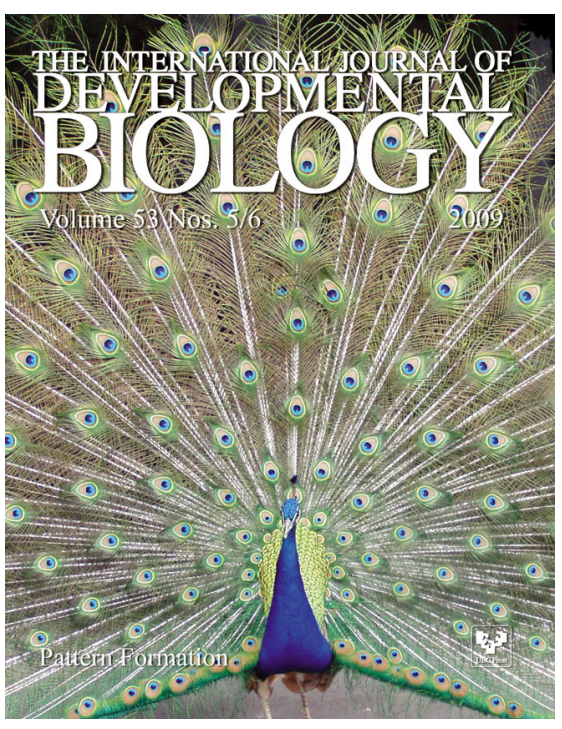

5 yr ISI Impact Factor $(2013)=2.879$
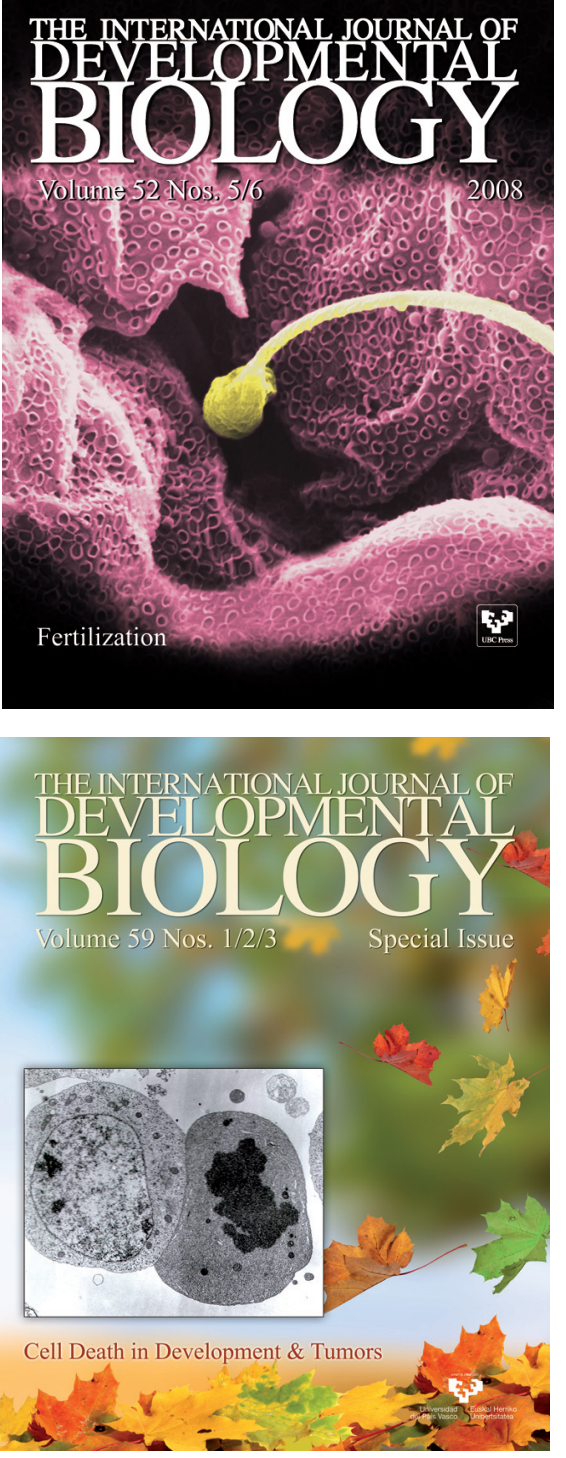